\title{
Studies on Acrylic Acid Modified Poly(Ester-Amide) Resins from Melia Azedarach Seed Oil - A Renewable Resource
}

\author{
SAGEER AHAMAD, GHAZALA IMRAN, S. A. AHMAD and A. HASNAT*
}

Natural Product and Polymer Research Laboratory, Department of Chemistry, G.F. College (M.J.P. Rohilkhand University) Shahjahanpur, U.P. 242001, India

hamdarshad@gmail.com

Received 2 May 2015 / Accepted 18 May 2015

\begin{abstract}
Syntheses of polymeric materials from renewable resources have been increased day by day due to fear of depletion of petroleum resources by the end of $21^{\text {st }}$ century. Vegetable oils especially obtained from different seeds are non-toxic; non-depletable and are friendly to the environment, attracted the attention of researcher recently for the utilization in making polymeric resins. In this work we have attempted to utilize Melia azedarach seed oil (MASO), a renewable resource abundantly available worldwide in the synthesis of acrylic acid modified poly (ester-amide) resins (AAMAPEA). The poly(ester-amide) (MAPEA) was prepared by the aminolysis of triglyceride with diethanol amine followed by the step-growth polymerization with phthalic acid. The MAPEA then treated with acrylic acid in different per hundred of resin (phr) to obtain a series of AAMAPEA resins. The synthesized polymeric resins have been characterized by measuring the physico-chemical properties and spectral analyses. Physicomechanical performances and protective ability of the polymeric films in different corrosive environments were also investigated as per standard methods. The studies reveals that AAMAPEA resin can be used as profitable anticorrosive coating material
\end{abstract}

Keywords: Melia azedarach, Acrylic acid, Poly(ester-amide), Renewable resource, Coating materials

\section{Introduction}

Poly(ester-amide) resins obtained from vegetable oil origin have hybrid advantageous properties of both ester and amide linkages in the polymeric chain, known for improved performances over normal alkyds in terms of hardness, impact resistance, flexibility, water vapor resistance, chemical resistance and thermal stability ${ }^{1-3}$. However, their use in formulation of versatile coating materials is restricted mainly due to their high curing temperature ${ }^{4,5}$ and low resistivity of the polymeric films towards scratch. Modification of oil based coating materials with metals, metalloids and organic moieties like styrene, vinyl acetate and other acrylic monomers reduces the curing temperature appreciably as well as impart the resistivity towards scratch hardnes ${ }^{6,7}$. 
Syntheses of polymeric materials from renewable resources have been increased day by day due to fear of depletion of petroleum resources by the end of $21^{\text {st }}$ century ${ }^{8}$. Vegetable oils especially obtained from seed oil are non-toxic; non-depletable attracted the attention of academia and scientist recently for the utilization in making polymeric resins. Common seed oils such as linseed ${ }^{9}$, castor $^{10}$, soybean ${ }^{11}$ and sunflower ${ }^{12}$ have been largely used in the synthesis of low molecular weight polymers like alkyds, epoxies, interpenetrating polymer network (IPN), poly(urethane)s, poly(ester-amide)s and many others ${ }^{1,11,13}$. These polymers are extensively used in the coatings, paints and adhesives industries. However some of these oil posses' medicinal values and other are edible too. There has been increasing demand of vegetable oil worldwide, consequently production of conventional seed oils do not kept the pace of demand, resulting increasing cost of final product. Therefore, it is required to utilize non-edible and non conventional seed oils for the synthesis of polymeric materials to arrest the escalating price of final product.

Melia azedarach belong to the Meliaceae family largely cultivated by the farmers in rural areas primarily for its wood. Its seed contain about $40 \%$ triglyceride oil of fatty acids ${ }^{14}$. Meager utilization of Melia azedarach seed oil (MASO) especially in the synthesis of polymeric materials prompted us to synthesize the acrylic acid modified poly(ester-amide)s using this oil as a starting material. In present work effort has been made to synthesized acrylic acid modified poly(ester-amide)s from Melia azedarach seed oil with the objective using a precursor obtained from a non-traditional renewable resources and enhancing the physico-mechanical performances of it by incorporating the acrylic acid, known for imparting harness and adhesion ${ }^{15,16}$. The synthesized resins were characterized by physicochemical analysis and by spectral studies. The physico-mechanical, physicochemical and protective efficiency of the polymeric films were also investigated.

\section{Experimental}

MASO was extracted from the crushed seeds of Melia azedarach collected from the different places of the Shahjahanpur District through the Soxhlet apparatus by using petroleum ether as a solvent $\left(60-80{ }^{\circ} \mathrm{C}\right)$. The results of physicochemical characterizations like specific gravity, refractive index, iodine value, saponification value, acid value and fatty acid composition of MASO is given in the Table 1. Phthalic acid, diethyl ether, acrylic acid and methanol were purchased from Merck, India. Diethanol amine of analytical grade procured from the s.d. Fine Chemicals, India and was distilled under reduced pressure before use.

Table 1. Characterization of MASO, HEMFA and MAPEA

\begin{tabular}{|c|c|c|c|c|}
\hline S. No. & Characterization & MASO & HEMAFA & MAPEA \\
\hline 1. & Oil content & 40 & - & - \\
\hline 2. & Gardener color & 6 & 6 & 8 \\
\hline 3. & Specific gravity & 0.930 & 0.938 & 0.956 \\
\hline 4. & Refractive index & 1.4691 & 1.4697 & 1.5062 \\
\hline 5. & Iodine value & 134.7 & 65.8 & 36.8 \\
\hline 6. & Acid Value & 4.45 & - & 7.42 \\
\hline 7. & Saponification value & 190.8 & - & 148.0 \\
\hline \multirow[t]{3}{*}{8.} & Fatty acid composition & & & \\
\hline & Saturated (Palmitic and stearic) & 11.4 & & \\
\hline & Unsaturated (Oleic and Linoleic) & 88.6 & & \\
\hline
\end{tabular}




\section{Syntheses}

$\mathrm{N}, \mathrm{N}$-bis(2-hydroxy ethyl) Melia azedarach oil fatty acid (HEMAFA) and Melia azedarach Poly(ester-amide) (MAPEA)

HEMAFA and MAPEA were synthesized and characterize as per previously reported method ${ }^{\circledR}$

\section{Acrylic acid modified poly(ester-amide) (AAMAPEA)}

Poly(ester-amide) of Melia azedarach seed oil (MAPEA) dissolved in xylene placed in four necked round bottom flask equipped with water condenser, nitrogen inlet tube, thermometer and mechanical stirrer. The content was heated up to $140{ }^{\circ} \mathrm{C}$ and then acrylic acid (AA) in different per hundred of resin (phr) along with bezoyl peroxide $(0.1 \mathrm{wt} \%$ of AA) added slowly in the same reaction mixture. The reaction mixture was allowed continue for two hrs to obtained AAMAPEA as end products. On completion of reaction, the product was cooled at room temperature. The excess of solvent removed in a rotary vacuum evaporator under reduce pressure.

\section{Characterization}

Physicochemical characterizations such as specific gravity, refractive index, viscosity, iodine value, hydroxyl value, saponification value of the polymers were performed as per standard reported laboratory methods ${ }^{4,6}$. The structural analysis of the polymer samples were carried out by spectral analysis. FT-IR spectrum of the AAMAPEA was recorded on FT-IR spectrophotometer (Perkin-Elmer Cetus instruments, Norwalk CT, USA) using a NaCl cell. ${ }^{1} \mathrm{H}$ NMR and ${ }^{13} \mathrm{C}$ NMR spectra were recorded on JEOL GSX $300 \mathrm{MHz}$ FX-1000 spectrometer using deuterated chloroform as a solvent and tetramethyl silane (TMS) as an internal standard.

\section{Preparation of coatings}

Coatings of AAMAPEA resins were prepared on mild steel strips, $70 \times 25 \times 1 \mathrm{~mm}$ size for pysico-mechanical test and $30 \times 10 \times 1 \mathrm{~mm}$ size for chemical/corrosion resistance test. The mild steel strips were polished on various grade of silicon carbide papers, then washed with distilled water, degreased with alcohol and carbon tetrachloride. They were dried under vacuum for several hours. The coatings were developed on these specimens by brush technique using a solution of $60 \mathrm{wt} \%$ of resins. Coated strips were baked at $160{ }^{\circ} \mathrm{C}$ for 30 minutes. Elcometer (Model 345; Elcometer instrument, Manchester, UK) was used to measure the coating thickness. The thicknesses of these coatings were found between $75 \pm$ $5 \mu \mathrm{m}$. The coated samples were evaluated for the scratch hardness (BS 3900), bending test on conical mandrel and impact resistance (IS: 101 part 5/Sec.31988) tests. The salt spray test (ASTM b117-94) was performed in a salt mist chamber containing $3.5 \mathrm{wt} \% \mathrm{NaCl}$ solutions. Chemical resistance tests of the coatings were performed in water, acid $(5 \mathrm{wt} \% \mathrm{HCl})$, alkali $(5 \mathrm{wt} \% \mathrm{NaOH})$ by placing them in 3 in. diameter porcelain dishes, in aforementioned media and periodic examinations were carried out until coating showed visual evidence of softening, deterioration in gloss, discoloration or weight loss.

\section{Results and Discussion}

Figure $1 \& 2$ depict the reaction scheme for the synthesis of MAPEA and AAMAPEA. The MAPEA was prepared by aminolysis of triglyceride oil with diethanol amine followed by the polycondensation of HEMAFA with phthalic acid. MAPEA resin was then treated with acrylic acid in different phr (Table 2) to obtain a series of AAMAPEA resins. 

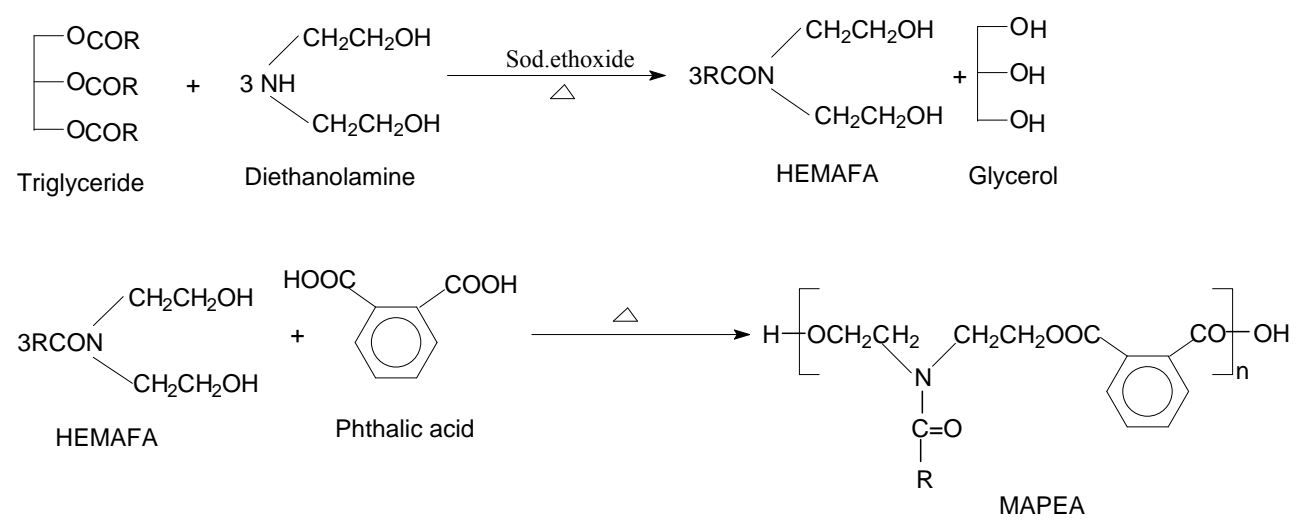

Figure 1. Synthesis of polyesteramide (MAPEA) R=Long alkyl chain of fatty aid of oil
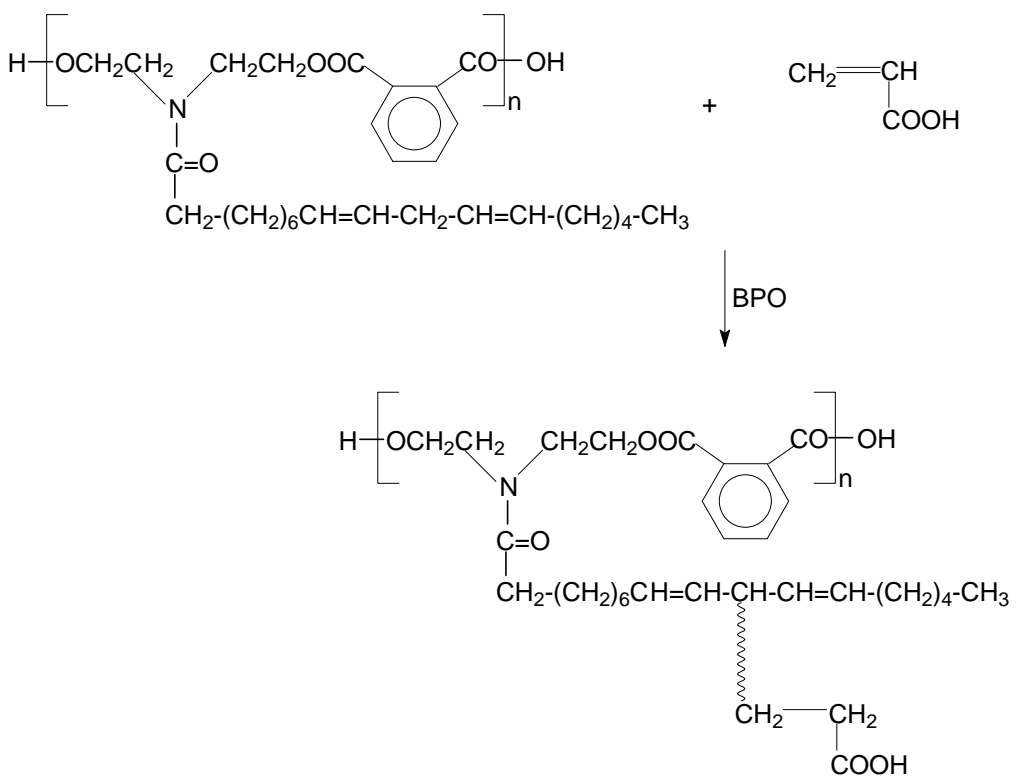

Figure 2. Rection scheme for formation of AAMAPEA

Acrylic acid grafted at allylic position of non-conjugated fatty acid chain, free radicals serve to modify the growth of acrylic acid chain by chain transfer mechanism. Acid value as well as hydroxyl values of the reaction mixture both decreases progressively during the conversion of HEMAFA to MAPEA. This is due to formation of repeating ester linkages by the condensation of these functional groups. On perusal of Table 2 it is reveals that, iodine value decreases gradually on increasing the acrylic acid (phr) content but remain constant for the same amount of MAPEA in the reaction. These observation indicates that grafting occur at allylic position without affecting the unsaturation of fatty acid.

IR spectrum of AAMAPEA shows the broad band at $3340 \mathrm{~cm}^{-1}$ for the O-H stretching vibration, band at $3060 \mathrm{~cm}^{-1}$ for Ar-H, bands at $2968 \mathrm{~cm}^{-1}$ and $2862 \mathrm{~cm}^{-1}$ for $\mathrm{CH}_{2}$ asymmetric and symmetric stretching vibrations respectively. The bands for carbonyl of repeating ester linkages, carboxylic aid and amide are appear at $1762 \mathrm{~cm}^{-1}, 1705 \mathrm{~cm}^{-1}$ and $1648 \mathrm{~cm}^{-1}$ respectively. 
Table 2. Characterization of AAMAPEA resins

\begin{tabular}{cccccc}
\hline Resin code $^{\mathrm{a}}$ & $\begin{array}{c}\text { Color } \\
\text { gardener }\end{array}$ & $\begin{array}{c}\text { Specific } \\
\text { gravity }\end{array}$ & $\begin{array}{c}\text { Inherent } \\
\text { viscosity, dL/g }\end{array}$ & $\begin{array}{c}\text { Refractive } \\
\text { index }\end{array}$ & $\begin{array}{c}\text { Iodine } \\
\text { value }\end{array}$ \\
\hline AAMAPEA-5 & 8 & 0.962 & 0.618 & 1.5076 & 34.48 \\
AAMAPEA-10 & 7 & 0.966 & 0.626 & 1.5084 & 32.82 \\
AAMAPEA-15 & 7 & 0.972 & 0.638 & 1.5090 & 31.52 \\
AAMAPEA-20 & 6 & 0.980 & 0.652 & 1.5124 & 30.20 \\
AAMAPEA-25 & 6 & 0.988 & 0.662 & 1.5126 & 29.42 \\
\hline
\end{tabular}

${ }^{a}$ Last digit indicates the loading of $\mathrm{AA}$ in $\mathrm{phr}$

The characteristic bands of aromatic ring appears at $1596,770 \mathrm{~cm}^{-1} .{ }^{1} \mathrm{H}$ NMR spectrum of AAMAPEA shows the peaks at $\delta=7.36-7.58 \mathrm{ppm}$ due to aromatic protons of phthalic acid while proton of double bonded carbons appear at $\delta=5.32-5.38 \mathrm{ppm}$. $\mathrm{CH}_{2}$ attached to nitrogen of amide appear at $\delta 3.76-4.08 \mathrm{ppm}$ where as allylic methylene and methine protons appear at 2.48 and $2.82 \mathrm{ppm}$ respectively. Sharp peak for $\mathrm{CH}_{2}$ adjacent to ester appears at $\delta=2.12 \mathrm{ppm}$, fatty amide chain $\mathrm{CH}_{2}$ appear as multiplet at $\delta 1.28-1.48 \mathrm{ppm}$ and proton of terminal methyl group at $\delta=0.92 \mathrm{ppm} .{ }^{13} \mathrm{C}$ NMR spectrum show the peaks at $\delta=174.8 \mathrm{ppm}$, $173.4 \mathrm{ppm}$ and $\delta 162.8 \mathrm{ppm}$ for the carbonyl of carboxylic acid, ester and amide. Closely spaced peaks at $\delta 132.8-128.6 \mathrm{ppm}$ due to carbon of aromatic ring ${ }^{18}$. Double bonded carbons appear at130.6-128.4 ppm where as carbons of allylic methine and methylene appears at $\delta 52.4$ and $\delta 44.6 \mathrm{ppm}$ respectively. Peaks for chain $\mathrm{CH}_{2}$ of fatty amide appears at $\delta 29.8$ $22.6 \mathrm{ppm}$ while carbon of terminal methyl group appears at $14.8 \mathrm{ppm}$.

\section{Coating properties}

The films of AAMAPEA containing different phr of AA (Table 3) developed on the mild steel coupons to investigate the physicomechanical as well as chemical/corrosion resistance performances. Scratch hardness values were found to be remarkably improved on increasing the AA content up to $20 \mathrm{phr}$. This is due to increase of pendent carboxylic group which provides sites for cross-linking by both physical as well as chemical phenomenon ${ }^{19}$. However, beyond this loading of AA no significance improvement was observed. All the coated samples show the good impact resistance more than $100 \mathrm{lb} / \mathrm{in}$, which indicates the good adhesion of the polymeric films to the metal surface. On increasing the AA content this property further improved up to the $20 \mathrm{phr}$, reasonably due to increase of polar groups in the AAMAPEA which impart good adhesion between the coating material and metal surface. However above than $20 \mathrm{phr}$ loading of AA in the polymeric resin this property start to deteriorate, presumably due to excessive cross-linking; which causes the internal stress and films becomes brittle. Furthermore, it has been observed that loading of AA beyond $25 \mathrm{phr}$ coating materials loss the fluidity and become unbrushable. This is due to excessive intermolecular hydrogen bonding among different polymeric chains. Gloss values of polymeric films increases on increasing the amount of AA, which expected for acrylic based coating material and increased cross-linked density both ${ }^{4,9}$. The polymeric films pass the bending test on $1 / 8$ conical mandrel up to the loading of $20 \mathrm{phr}$ of AA, a characteristic of vegetable oil based coating materials however, small cracks were observed in case of AAMAPEA-25 presumably due to the excessive cross-linking which make the film brittle. Table 3 indicates that chemical resistance ability of AAMAPEA improved up to $20 \mathrm{phr}$ of AA. AAMAPEA-20 among all AAMAPEA systems shows the best performance in water, acidic and saline environments. On perusal of Table 3 it has been observed that chemical resistivity of the polymer film start to deteriorate while increasing the component of AA 
more than $20 \mathrm{phr}$. This is due to excessive cross-linking make the film brittle and a cause of shrinkage of the film at edges. Coatings of AAMAPEA show poor performance in alkaline medium like other oil based coating materials.

Table 3. Physicomechanical and chemical/corrosion resistance properties of AAMAPEA coatings

\begin{tabular}{|c|c|c|c|c|c|c|c|c|}
\hline \multirow[b]{2}{*}{ Resin $\operatorname{code}^{\mathrm{a}}$} & \multirow[b]{2}{*}{$\begin{array}{c}\text { Scratch } \\
\text { hardness } \\
(\mathrm{Kg})\end{array}$} & \multirow[b]{2}{*}{$\begin{array}{l}\text { Impact } \\
\text { resistance } \\
\text { (lb/in) }\end{array}$} & \multirow[b]{2}{*}{$\begin{array}{l}\text { Bending } \\
\text { test }\left(1 / 8^{\prime}\right)\end{array}$} & \multicolumn{5}{|c|}{ Chemical/corrosion resistance $^{b}$} \\
\hline & & & & $\begin{array}{c}\text { Gloss at } \\
45^{\circ}\end{array}$ & $\begin{array}{c}\mathrm{H}_{2} \mathrm{O} \\
10 \text { days }\end{array}$ & $\begin{array}{c}\mathrm{HCl} \\
(5 \%) \\
10 \text { days }\end{array}$ & $\begin{array}{c}\mathrm{NaOH} \\
(3 \%) \\
(3 \mathrm{hrs})\end{array}$ & $\begin{array}{c}\mathrm{NaCl} \\
(3.5 \%) \\
10 \text { days }\end{array}$ \\
\hline AAMAPEA-5 & 1.5 & 100 & Pass & 38 & $\mathrm{C}$ & $\mathrm{B}$ & A & $\mathrm{C}$ \\
\hline AAMAPEA-10 & 2.5 & 150 & Pass & 44 & $\mathrm{D}$ & $\mathrm{D}$ & B & D \\
\hline AAMAPEA-15 & 3.0 & 200 & Pass & 56 & $\mathrm{E}$ & $\mathrm{D}$ & $\mathrm{C}$ & $\mathrm{D}$ \\
\hline AAMAPEA-20 & 3.5 & 200 & Pass & 64 & E & E & $\mathrm{D}$ & $\mathrm{D}$ \\
\hline AAMAPEA-25 & 3.5 & 150 & Fail & 66 & $\mathrm{D}$ & $\mathrm{C}$ & B & $\mathrm{C}$ \\
\hline
\end{tabular}

${ }^{a}$ Last digit indicates the loading of $A A$ in $p h r,{ }^{b} A=$ film completely removed; $B=$ film cracked and partially removed; $C=$ loss in gloss; $D=$ slight loss in gloss; $E=$ unaffected

\section{Conclusion}

From this study it can be concluded that the non-edible, non-traditional and annually renewable Malea azedarach seed oil can be utilized successfully for the synthesis of acrylic acid modified poly(ester-amide) resin. The synthesized resins were characterized by taking physico-chemical analyses and spectral studies. Physicomechanical performances and corrosion/chemical resistance ability of the polymeric films were also evaluated. AAMAPEA resins show good performances in acidic, humid and saline environments. Furthermore, AAMAPEA-20 shows the best performance among AAMAPEA resins. The syntheses of AAMAPEA resins therefore provide a fruitful route for the utilization of MASO abundantly available worldwide.

\section{Acknowledgement}

The authors would like to thank the authorities of G. F. College, Shahjahanpur, UP, India for providing necessary facilities for carrying out this study.

\section{References}

1. Islam M R, Beg M D H and Jamari S S, J Appl Polym Sci., 2014, 131(18), 4078740799; DOI:10.1002/app.40787

2. Zafar F, Ashraf S M and Ahmad S, Reactive Functional Polym., 2007, 67(10), 928935; DOI:10.1016/j.reactfunctpolym.2007.05.018

3. Lebarbe T, Maisonneuve L, Nguyen T H N, Gadenne B, Alfos C and Cramail H, Polym Chem., 2012, 3, 2842-2851; DOI:10.1039/C2PY20394D

4. Ahmad S, Ashraf S M, Hasnat A, Yadav S and Jamal A, J Appl Polym Sci., 2001, 82(8), 1855-1865; DOI:10.1002/app.2029

5. Ansrai S H, Naseem M, Hasnat A \& Ahmad S A, Biosci Biotech Res Asia, 2011, 8(2), 829-832; DOI:10.13005/bbra/944

6. Ahmad S, Ashraf S M, Naqvi F, Yadav S and Hasnat A, Prog Org Coat., 2003, 47(2), 95-102; DOI:10.1016/S0300-9440(03)00015-8

7. Ahmad S, Ashraf S M, Naqvi F, Yadav S and Zafar F, J Macromolecular Sci, Part A: Pure and Appl Chem., 2006, 43(9), 1409-1419; DOI:10.1080/10601320600820280 
7. Ahmad S, Ashraf S M, Sharmin E, Zafar F and Hasnat A, Prog Crystal Growth Charact Mat.., 2002, 45(1-2), 83-88; DOI:10.1016/S0960-8974(02)00031-1

8. Ahmad S, Ashraf S M, Kumar S, Alam M and Hasnat A, Indian J Chem Technol., 2005, 12, 193-197.

9. Ansari S H, Imran G, Naseem M, Ahmad S A and Hasnat A, Orient J Chem., 2012, 28, 607-612.

10. Guner F S, Yagci Yand Erciyes A T, Progress Polym Sci., 2006, 31(7), 633-670; DOI:10.1016/j.progpolymsci.2006.07.001

11. Ahmad S, Ashraf S M, Naqvi F, Yadav S and Hasnat A, J Polym Mater., 2001, 18, 53-60.

12. Lochab B, Varma I K and Bijwe J, Adv Mater Phys Chem., 2012, 2(4B), 221-225; DOI:10.4236/ampc.2012.24B056

13. Ambastha S P, Useful Plants of India, CSIR, New Delhi, 1986.

14. Ahmad S, Ashraf S M, Hasnat A and Noor A, Indian J Chem Technol., 2001, 8, 176180.

15. Sounders K J, Organic Polymer Chemistry, $2^{\text {nd }}$ Edn., Chapman and Hall, USA, 1988.

16. Ahamad S, Imran G, Ahmad S A and Hasnat A, Orient J Chem., 2015, 31(2), 1169117; DOI:10.13005/ojc/310271.

17. Silverstein R M, Bassler G C and Morril T C, Spectroscopic Identification of Organic Compounds, $5^{\text {th }}$ Edn., John Wiley Sons, New York, 1991.

18. Zafar F, Ashraf S M and Ahmad S, Chem Chem Technol., 2008, 2(4), 285-293. 